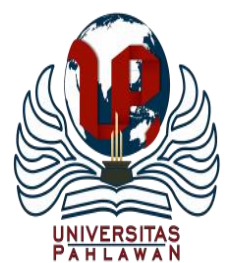

Edukatif : Jurnal Ilmu Pendidikan Volume 3 Nomor 3 Tahun 2021 Halm 649 - 655 EDUKATIF: JURNAL ILMU PENDIDIKAN

Research \& Learning in Education

https://edukatif.org/index.php/edukatif/index

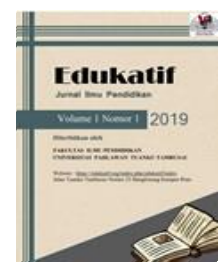

\title{
Koherensi Program Pertukaran Pelajar Kurikulum Merdeka Belajar Kampus Merdeka dan General Education
}

\author{
Aiman Faiz ${ }^{1 凶}$, Purwati ${ }^{2}$ \\ Universitas Muhammadiyah Cirebon, Indonesia ${ }^{1}$ \\ Universitas Pendidikan Indonesia, Kampus Tasikmalaya, Indonesia ${ }^{2}$ \\ E-mail : aimanfaiz@umc.ac.id ${ }^{1}$, Purwati_purwati@upi.edu $^{2}$
}

\begin{abstract}
Abstrak
Tujuan artikel penelitian ini mengulas konsep Merdeka Belajar yang berkoherensi dengan kurikulum general education. Saat ini Indonesia memasuki era tatanan dan konsep kurikulum baru yaitu Merdeka Belajar Kampus Merdeka. Dalam kurikulum MB-KM terdapat program pertukaran pelajar yang memberikan kesempatan mahasiswa memperdalam bidang keilmuan yang tidak didapatkan di Program Studinya. Metode penelitian yang digunakan adalah library research, untuk menyusun koherensi antara konsep MB-KM dengan general education, peneliti menggali berbagai literatur dari artikel dan buku yang relevan. Hasil studi pustaka menjelaskan, untuk menghadapi kondisi zaman yang kompleks, maka diperlukan pembaharuan dalam kurikulum perguruan tinggi agar mahasiswa memiliki kemampuan yang memiliki kemampuan memecahkan permasalahan dengan berbagai disiplin keilmuan. Esensi dalam MB-KM program pertukaran pelajar dan general education adalah memfasilitasi mahasiswa untuk bisa mengambil ilmu dari bidang keilmuan lain yang belum pernah dipelajarinya sehingga mahasiswa dapat berpikir secara luwes dan komprehensif. Selain membekali dengan konsep multidisiplin atau transdisiplin keilmuan, program pertukaran pelajar juga memberikan bekal dan penanaman karakter untuk mengenal suku, bangsa, budaya, ras dan agama, sehingga memperkuat esensi nilai persatuan dan kesatuan bangsa. Dengan demikian, lintas disiplin keilmuan merubah paradigma baru bahwa setiap bidang keilmuan memiliki kesempatan untuk bisa dikolaborasikan dengan ilmu lain melalui kurikulum MB-KM yang berkoherensi dengan kurikulum general education.
\end{abstract}

Kata Kunci: Merdeka belajar, kampus merdeka, pertukaran pelajar, general education.

\begin{abstract}
The purpose of this research article is to review the concept of Merdeka Belajar which is in comherence with the general education curriculum. Currently Indonesia is entering an era of new curriculum settings and concepts, namely Merdeka Belajar Kampus Merdeka. In the MB-KM curriculum there is a student exchange program that provides students with opportunities to deepen the scientific field that is not obtained in their Study Program. The research method used is library research, to establish the coherence between the concept of MB-KM and general education, researchers explore various literature from relevant articles and books. The results of the literature study explained, to face the complex conditions of the era, it is necessary to update the college curriculum so that students have the ability to solve problems with various scientific disciplines. The essence in MB-KM student exchange program and general education is to facilitate students to be able to take knowledge from other scientific fields that they have never studied so that students can think flexiblely and comprehensively. In addition to providing with the concept of multidisciplinary or scientific transdisciplinary, the student exchange program also provides provisions and planting characters to know the tribe, nation, culture, race and religion, thus strengthening the essence of the value of unity and unity of the nation. Thus, cross-disciplinary science changes the new paradigm that every scientific field has the opportunity to be collaborated with other sciences through the MB-KM curriculum that is in collaboration with the general education curriculum.
\end{abstract}

Keywords: Merdeka learning, independent campus, student exchange, general education

Copyright (c) 2021 Aiman Faiz, Purwati

$\square$ Corresponding author

Email : aimanfaiz@umc.ac.id

DOI : https://doi.org/10.31004/edukatif.v3i3.378

ISSN 2656-8063 (Media Cetak)

ISSN 2656-8071 (Media Online)

Edukatif : Jurnal Ilmu Pendidikan Vol 3 No 3 Tahun 2021

p-ISSN 2656-8063 e-ISSN 2656-8071 
650 Koherensi Program Pertukaran Pelajar Kurikulum Merdeka Belajar Kampus Merdeka dan General Education-Aiman Faiz, Purwati

DOI: https://doi.org/10.31004/edukatif.v3i3.378

\section{PENDAHULUAN}

Pendidikan saat ini memasuki konsep baru yang tersusun dalam kurikulum Merdeka Belajar - Kampus Merdeka yang berorientasi pada penguasaan yang harus dimiliki mahasiswa dengan berbagai bidang keilmuan, agar menjadi lulusan yang memiliki kompetensi secara komprehensif. Implementasi Kampus Merdeka membuka jalan bagi mahasiswa yang ingin memperdalam bidang keilmuan yang tidak ada didalam Prodi-nya. Acuan yang digunakan dalam MB-KM ini adalah Permendikbud nomor 3 tahun 2020 terkait Standar Nasional Pendidikan Tinggi yang memfasilitasi hak bagi mahasiswa untuk dapat mengikuti program perkuliahan diluar perguruan tinggi yang berbeda paling lama dua semester atau sepadan dengan 40 SKS, dan dapat mengikuti perkuliahan di prodi yang berbeda di perguruan tinggi yang sama selama satu semester atau sepadan dengan 20 SKS. Tentunya aturan tersebut menyesuaikan dengan aturan dan ketentuan bagi dosen yang memiliki keterampilan dan kemampuan dalam mengimplementasikan kerjasama kurikulum MB-KM (Tohir M, 2020). Kurikulum ini mendorong agar mahasiswa memiliki beragam kompetensi yang tertuang dalam Permendikbud nomor 3 tahun 2020 (Susetyo, 2020: 29).

Kurikulum Merdeka Belajar - Kampus Merdeka memiliki konsep yang baru dimana pola MB-KM ingin menghapuskan paradigma linieritas yang menjadi jurang penghalang diantara bidang-bidang keilmuan. Mengingat kehidupan saat ini yang semakin kompleks menekankan aspek wawasan yang lebih luas dan komprehensif lagi, guna mempersiapkannya tentu memerlukan berbagai kolaborasi keilmuan baik secara multidisiplin maupun interdisiplin keilmuan (Faiz, 2020: 1). Seperti yang diungkapkan (Abdullah et al., 2014: 6) bahwa ketika keilmuan beraromakan konflik dan saling membatasi diri, maka tentu tidaklah nyaman dalam menghadapi kehidupan yang semakin kompleks.

Memang dengan adanya spesialisasi keilmuan merupakan sebuah keniscayaan, karena sifat manusia yang memiliki kemampuan terbatas (Siswanto, 2015: 378). Hadirnya konsep kurikulum MB-KM yang diprakarsai oleh Mendikbud Nadiem Makariem memecahkan kebuntuan, dan memberikan pencerahan bagi para ilmuan yang memiliki dinding pembatas diantara berbagai keilmuan. Akan tetapi diantara disiplin ilmu tersebut masih bisa saling menjaga identitasnya, tetapi tetap bisa saling terbuka untuk berdialog dan berdiskusi antar bidang disiplin keilmuan (Abdullah et al., 2014: 8). Kebijakan visioner yang diprakarsai oleh Mendikbud diharapkan mampu memberikan dampak posifit bagi kemajuan perguruan tinggi dan lulusan dari perguruan tinggi di Indonesia (Arifin, S., \& Muslim, 2020: 3).

Kebijakan yang visioner ini layak untuk diapresiasi, terlebih dengan latar belakang Menteri Pendidikan dan Kebudayaan yang bukan dari kalangan dunia pendidikan mampu memberikan kebrakan kebijakan yang dirasakan berbagai kalangan mampu membawa kemajuan perguruan tinggi Indonesia.

Begitu kira-kira harapan yang diinginkan oleh Kemendikbud Nadiem Makarim dalam mewujudkan generasi yang unggul pada tahun 2045.

Sebenarnya konsep MB-KM masih memiliki keterkaitan dengan konsep General Education yang berasal dari konsep pendidikan luar negeri. Menurut UNESCO, konsep general education mampu mendekatkan, mengkolaborasikan berbagai keilmuan. General education menjadi salah satu cara yang mampu mempererat dan menghapuskan kesenjangan dari berbagai rumpun lintas disiplin keilmuan (Faiz, 2020: 2). Pentingnya memahami Core value dalam General Education/ Pendidikan Umum bertujuan sebagai upaya membentuk manusia agar memiliki keseimbangan dari pengetahuan, berpikir, berperasaan, kesadaran, kreatif dan terampil yang diintegrasikan dengan berbagai bidang keilmuan (Sauri, 2016:2). Untuk mengkaji lebih dalam lagi terkait irisan antara Kurikulum Merdeka Belajar - Kampus Merdeka dan General Education yang belum pernah ada sebelumnya maka peneliti akan menguraikannya pada bagian pembahasan. 
651 Koherensi Program Pertukaran Pelajar Kurikulum Merdeka Belajar Kampus Merdeka dan General

Education-Aiman Faiz, Purwati

DOI: https://doi.org/10.31004/edukatif.v3i3.378

\section{METODE PENELITIAN}

Dalam penelitian ini, metode yang menjadi rujukan adalah library research. Untuk mendukung asumsi pemikiran peneliti menggunakan tinjauan literatur, yang memiliki kesesuaian dengan topik pembahasan berupa artikel, buku dan pemahaman para ahli (Faiz \& Kurniawaty, 2020: 158). Adapun sumber rujukan yang menjadi referensi diantaranya buku dan jurnal yang berkaitan dengan konsep Merdeka Belajar Kampus Merdeka dan konsep-konsep general education yang ada di Indonesia maupun di luar negeri, hal ini guna memadukan keterkaitan konsep MB-KM dengan. Tipikal penelitian library research-pun tersmasuk kedalam bagian penelitian kualitatif, Bogdan dan Biklen menyimpulkan penelitian library research merupakan bagian dari penelitian kualitatif (Waston, 2016: 82), karena penelitian ini mengupas konsep yang berkaitan antara kurikulum MB-KM dengan General Education.

\section{HASIL DAN PEMBAHASAN PENELITIAN}

Perubahan tatanan dunia secara global perlu dibarengi dengan perubahan keterampilan yang dibutuhkan. Perguruan tinggi harus memberikan bekal kepada mahasiswa dengan memegang empat core value yaitu; adaptasi, resiliensi, integritas dan kompetensi. Selain empat core value tersebut, mahasiswa juga harus memiliki kemampuan yang harus dikuasai agar mampu bersaing dengan lulusan pada kelas nasional maupun internasional diantaranya; mampu berkomunikasi, mampu berpikir kritis dan memiliki kreativitas, receptive mind, memiliki rasa kesadaran multikultur, mampu beradaptasi, memiliki kemampuan bekerja dalam lintas bidang keilmuan, mampu mengolah data science yang suatu saat akan bermuara pada perspektif keIndonesiaan. Tentunya dalam hal ini perguruan tinggi harus bersikap adaptif memandang perubahan konsep secara global, dalam mempersiapkan hal tersebut. Aspek lain yang harus persiapan perguruan tinggi, mahasiswapun harus bisa meningkatkan keterampilannya sendiri. Masa yang akan datang persiapan yang harus dibangun oleh perguruan tinggi adalah keterampilan memecahkan permasalahan dan kemampuan berpikir secara luwes (complex problem solving \& cognitive flexibility) (Oey-Gardiner et al., 2017: 177). Untuk itu, Mendikbud Nadiem Makariem membuat konsep yang memiliki tujuan dan harapan yang sesuai dengan kebutuhan dan tantangan zaman. Konsep tersebut dituangkan kedalam kurikulum MB-KM.

Jika mencari referensi lebih dalam, sebenarnya irisan kurikulum MB-KM berkaitan dengan konsep liberal arts atau sekarang dikenal dengan general education. Tujuan general education sendiri untuk memberi kesempatan pembelajar dalam hal ini mahasiswa untuk membuka tatanan konsep baru dengan memberikan kesempatan untuk berkolaborasi dengan ilmu lain. Di dalam kurikulum general education yang diterapkan oleh perguruan tinggi diluar negeri adalah untuk bekerjasama membuat koherensi pengalaman bagi mahasiswa (Ristekdikti, 2017: 25). Contoh, mahasiswa Teknik Komputer membicarakan terkait cara membuat aplikasi terkait dengan mahasiswa ilmu pertanian, yang juga diberi perspektif berbeda dari mahasiswa dari ilmu filsafat, sosial dan kesehatan. Hal ini akan memberikan perspektif masing-masing yang mungkin tidak pernah terlintas sebelumnya. Hal ini akan memberikan paradigma baru agar mahasiswa dan dosen mampu berpikir kolaboratif dan tidak kaku/ luwes terhadap sudut pandang orang lain sebagaimana diungkapkan Henry (1952 dalam Sauri, 2016) bahwa general education tidak mengarahkan pemikiran manusia kepada hal yang kaku dan sempit. Hal ini juga tentu akan meningkatkan aspek saling menghargai antar keilmuan masingmasing.

Salah satu program MB-KM yang paling relevan dengan konsep kurikulum General Education adalah program kegiatan pertukaran pelajar/ mahasiswa yang diantaranya; 1) mengikuti perkuliahan dikampus lain (di dalam negeri maupun di luar negeri; 2) membangun persahabatan mahasiswa; 3) mengadakan proses pendidikan untuk menutupi disparitas pendidikan (dalam negeri maupun luar negeri) (Tohir M, 2020: 6). Jika ditelaah dari program pertukaran pelajar ini, ada pesan yang terdapat di dalam program tersebut, diantaranya 
652 Koherensi Program Pertukaran Pelajar Kurikulum Merdeka Belajar Kampus Merdeka dan General

Education-Aiman Faiz, Purwati

DOI: https://doi.org/10.31004/edukatif.v3i3.378

memahami keilmuan dari berbagai perspektif, dengan mengenalkan, mempererat persatuan dan kesatuan melalui budaya, suku, rasa, agama dan bahasa.

Sangat positif sekali kegiatan pertukaran pelajar ini mengingat Indonesia negara yang memiliki keberagaman yang kaya akan budaya sehingga dengan relevansi kebijakan tersebut mampu membentuk mahasiswa menjadi warga negara yang baik (Itok Dwi Kurniawan, Harjon, Sri Wahyuningsih Yulianti, 2020 :11). Kekayaan budaya dapat menjadi kekuatan namun sekaligus kelemahan. Untuk itu, diperlukan penguatan nilai empati dan persatuan yang diimplementasikan dalam kegiatan pertukaran pelajar. Disadari atau tidak, hal ini memberikan penguatan positif bagi karakter individu bahkan karakter bangsa dengan proses habituasi (Faiz, 2019: 2). Sehingga tercapai mahasiswa lulusan yang memiliki kapasitas secar utuh dan berkarakter. Jika di visualisasikan keterkaitan antara kurikulum MB-KM dengan General Education sebagai berikut:

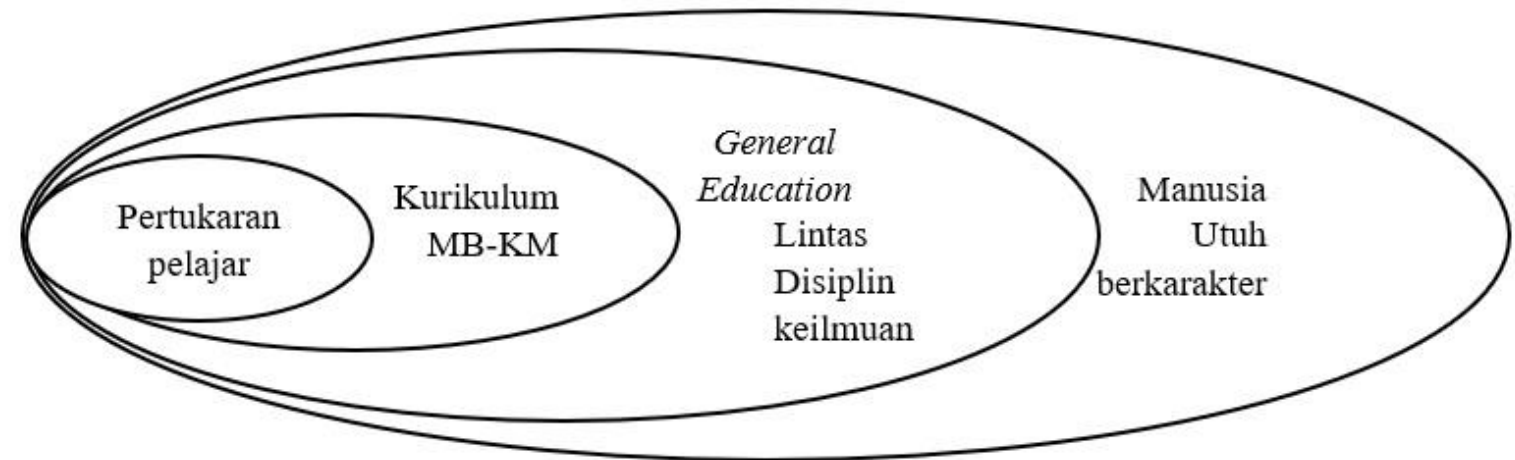

Gambar 1. Keterkaitan kurikulum MB-KM dengan General Education

Sumber: Peneliti 2021

Jika ditelaah lebih dalam lagi, mungkin secara historis terlahirnya kurikulum MB-KM ini merespon catatan yang menohok saat rapat kerja Kemenristekdikti, (2017:36) yang menyebutkan bahwa lulusan di perguruan tinggi Indonesia, dalam aspek berpikir tingkat tinggi (Higher order of thinking skill) para alumni masih belum mampu. Sehingga ada terindikasi, para lulusan atau alumni kemampuan berpikirnya tingkat rendah (lower order of thinking skill). Hal ini, dikarenakan mahasiswa atau bahkan dosennya masih mengandalkan pola pemikiran yang monodisiplin yang tinggi. Sehingga sulit untuk mencapai kualitas lulusan dengan kemampuan yang komprehensif.

Dari hasil kajian pustaka, Kemenristekdikti, (2017: 43-44) merangkum hasil studi mengenai sumber daya manusia yang dihasilkan pendidikan tinggi di Indonesia yang menyebutkan Indeks Pembangunan Manusia (IPM) Indonesia masih rendah sehingga berakibat pada kurangnya produktivitas dan kemampuan daya saing dalam perekonomian nasional. Untuk itu, rekonstruksi kurikulum di perguruan tinggi menjadi sebuah keharusan, diantaranya kurikulum yang saat ini dikembangkan (MB-KM). Hal ini bertujuan agar kualitas SDM yang dimiliki Indonesia mampu meningkat agar daya saing dan produktivitas juga meningkat. Dengan demikian, untuk dapat menjadikan bangsa yang makmur, maka lulusan perguruan tinggi harus mendapat peningkatan melalui integrasi keilmuan dan pengembangan karakter. Konsep kurikulum MB-KM yang secara garis besar mengambil konsep general education, diharapkan menjadi alternatif dalam menghadapi kondisi zaman dan memberi bekal bagi mahasiswa agar bisa menjadi manusia yang berkontribusi dalam berbagai pembangunan nasional dan mampu mengembangkan pemikiran sebagai problem solver bukan sebagai complainer (Ristekdikti, 2017: 52). Karena melalui pengembangan kurikulum pendidikan menjadi salah satu aspek terpenting bagi kehidupan dan harus sesuai dengan perkembangan zaman (Siregar et al., 2020: 142). 
Menurut Oey-gardiner (2018: 258) konsep yang terdapat dalam general education adalah merekatkan dan menghubungkan secara instrinsik dan sistematis antara berbagai disiplin keilmuan diantaranya sains, ilmu sosial dan humaniora, antara kemampuan berpikir ilmuah dan pemikiran kemanusiaan. Konsep tersebut, jika di visualisasikan sebagai berikut:

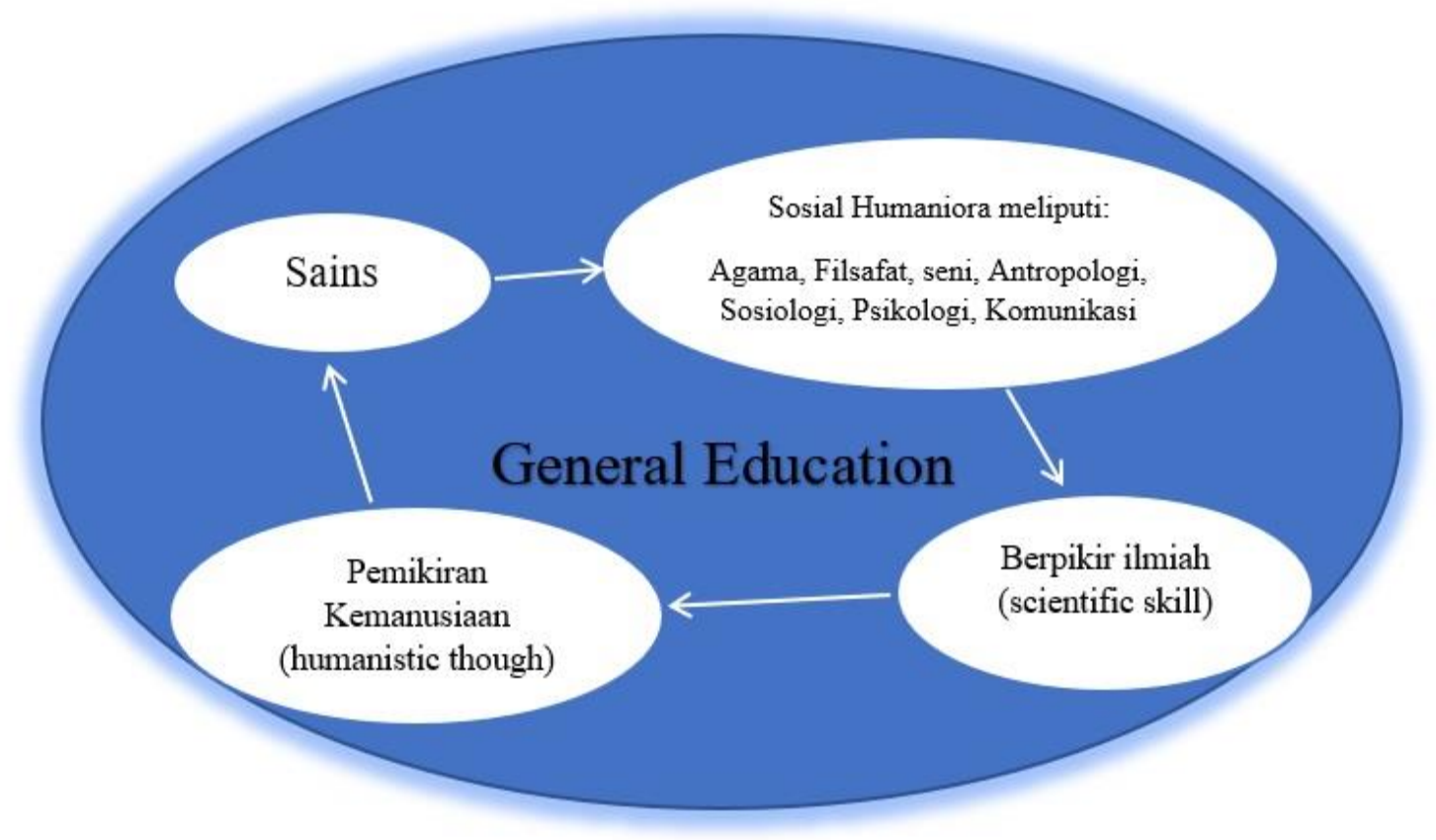

Gambar 2. Konsep General Education

Sumber : Oey-gardiner, (2018: 258)

Konsep integrasi dalam General Education di atas, secara garis besar merupakan konsep yang diadopsi dari pemikiran Phenix (1964: 270) yang mengungkapkan bahwa lingkup general education mencakup enam bidang makna, yaitu: symbolics, empirics, esthetics, synnoetics, ethics, and synoptics. Dengan kata lain, Phenix menyebutnya dengan enam pola dasar mengenai makna, yakni: in language, science, art, personal knowledge, ethics, and synoptics. Seperti pendapat Phenix (1964, hlm. 270) "The curriculum should at least provide for learnings in all six of the realms of meaning: symbolics, empirics, esthetics, synnoetics, ethics, and synoptics. If any of the six is missing, the person lacks a basic ingredient in experience". Hal ini dikarenakan general education haruslah memuat ketentuan-ketentuan belajar yang diperlukan untuk pengembangan esensi kemanusiaan seseorang. Dengan demikian, general education haruslah menjadi pelopor dalam menyiapkan manusia secara terorganisir yang tercermin dari tujuan konsep pendidikan melalui landasan filosofis, karena bagi Phenix, tujuan pendidikan ialah penghayatan terhadap dunia dan pengenalan dari berbagai makna secara teritegrasi dengan lintas keilmuan.

Dengan demikian, keterikatan konsep yang sama antara MB-KM dengan general education memberikan jalan pemahaman bagi pedidikan tinggi agar lebih humanis dan holistik dengan berbagai lintas keilmuan. General education memberikan gambaran bahwa antara ilmu tidak ada pembatas yang saling mengklaim, namun kurikulum MB-KM dan general education menyadarkan bahwa manusia itu harus saling berkolaborasi dengan komunikatif, dan kritis untuk menghasilkan ide kreatif yang belum pernah ada sebelumnya, seperti kemampuan yang harus di miliki pada abad-21 ini. Harapan dengan adanya artikel ini bisa menambah khazanah keilmuan baik secara praktis maupun teoritis, mampu memberikan pemahaman konsep baru yang sebelumnya mungkin belum dipahami terkait integrasi kurikulum MB-KM dengan kurikulum general education. 
654 Koherensi Program Pertukaran Pelajar Kurikulum Merdeka Belajar Kampus Merdeka dan General Education-Aiman Faiz, Purwati

DOI: https://doi.org/10.31004/edukatif.v3i3.378

\section{KESIMPULAN}

Untuk menghadapai kondisi zaman yang kompleks, maka diperlukan pembaharuan dalam kurikulum perguruan tinggi agar mahasiswa memiliki kemampuan yang memiliki kemampuan memecahkan permasalahan dengan berbagai disiplin keilmuan. Konsep kurikulum MB-KM program pertukaran pelajar yang diimplementasikan di perguruan tinggi memiliki tujuan untuk bisa mengembangkan berbagai disiplin keilmuan yang berdasarkan hasil penelitian secara irisan konseptual, memiliki kesamaan dengan kurikulum general education. Kesamaan tersebut terlihat dari implementasi yang merekonstruksi output yang harus dipersiapkan perguruan tinggi agar memiliki kemampuan secara komprehensif dengan mengutamakan lintas disiplin keilmuan. Lintas disiplin keilmuan memberubah paradigma baru bahwa dengan tantangan yang semakin kompleks, ilmu harus bisa dikolaborasikan dengan ilmu lain agar lulusan perguruan tinggi mampu mengurai berbagai permasalahan yang ada dengan mempererat dan menutup jurang antara berbagai rumpun ilmu dengan program pertukaran pelajar kurikulum MB-KM. Selain itu, secara konseptual implementasi program pertukaran pelajar kurikulum MB-KM juga menjadi cara untuk mengenalkan berbagai budaya dan kebiasaan di kampus lain, memberikan dampak positif bagi karakter mahasiswa agar mahasiswa mau mengenali berbagai suku, budaya, bahasa dan kearifan lokal. Hal tersebut bertujuan untuk mempererat persatuan dan kesatuan antar warga negara dengan berkolaborasi secara komunikatif, dan kritis untuk menghasilkan ide kreatif yang belum pernah ada sebelumnya, seperti kemampuan yang harus di miliki di abad-21 ini.

\section{DAFTAR PUSTAKA}

Abdullah, A., Mulkhan, Munir, A., Machasin, Asy’arie, M., Nasution, K., Ilyas, H., \& Faiz, F. (2014). Praksis Paradigma Integrasi-Interkoneksi dan Transformasi Islamic Studies di UIN Sunan Kalijaga.

ARIFIN, S., \& Muslim, M. O. H. (2020). Tantangan Implementasi Kebijakan "Merdeka Belajar, Kampus Merdeka" pada Perguruan Tinggi Islam Swasta di Indonesia. Jurnal Pendidikan Islam Al-Ilmi, 3(1)., 111 .

Faiz, A. (2019). Program Pembiasaan Berbasis Pendidikan Karakter Di Sekolah Aiman Faiz karena kualitas karakter menentukan. PGSD Universitas Muhammadiyah Cirebon, 5(20). https://doi.org/htps://doi.org/10.32534/jps.v5i2.741

Faiz, A. (2020). Pendidikan nilai dan karakter dalam perspektif pendidikan umum di perguruan tinggi. Sosioreligi, 18(2), 1-7.

Faiz, A., \& Kurniawaty, I. (2020). Konsep Merdeka Belajar Pendidikan Indonesia Dalam Perspektif Filsafat Progresivisme. Konstruktivisme: Jurnal Pendidikan Dan Pembelajaran. https://doi.org/https://doi.org/10.35457/konstruk.v12i2.973

Henry, N. B. (1952). The Fifty-First Year Book of The National Society For The Study Of Education (Part 1Ge). The University Of Chichago Press.

Itok Dwi Kurniawan, Harjon, Sri Wahyuningsih Yulianti, I. S. (2020). ANALISIS KONSEP KAMPUS MERDEKA DALAM PERSPEKTIF PENDIDIKAN KEWARGANEGARAAN. Jurnal Global Citizen Jurnalilmiah, 9(2), 51-62.

Oey-gardiner, M. (2018). Tantangan Pendidikan Tinggi Indonesia di Era Disrupsi dan Globalisasi. Sdg Center Unpad, 1-9.

Oey-Gardiner, M., Rahayu, S. I., Abdullah, M. A., Effendi, S., Darma, Y., Dartanto, T., Aruan, C. D., \& SANDI, P. A. (2017). Era Disrupsi: Peluang Dan Tantangan Pendidikan Tinggi Indonesia. https://www.ksi-indonesia.org/file_upload/Era-Disrupsi--Peluang-dan-Tantangan-Pendidikan-Ti06Jul2017054316.pdf 
655 Koherensi Program Pertukaran Pelajar Kurikulum Merdeka Belajar Kampus Merdeka dan General Education - Aiman Faiz, Purwati DOI: https://doi.org/10.31004/edukatif.v3i3.378

Phenix, P. H. (1964). Realm of Meaning. McGraw-Hill Book Company.

Ristekdikti. (2017). Memandang Revolusi Industri Dan Dialog Pendidikan Karakter Di Perguruan Tinggi Indonesia. Direktorat Pembelajaran Direktorat Jenderal Pembelajaran Dan Kemahasiswaan Kementerian Riset, Teknologi, Dan Pendidikan Tinggi.

Sauri, S. (2016). Konsep Pendidikan Umum. Tidak ditemukan.

Siregar, N., Sahirah, R., \& Harahap, A. A. (2020). Konsep Kampus Merdeka Belajar di Era Revolusi Industri 4.0. Fitrah: Journal of Islamic Education, 1(1), 141-157.

Siswanto, S. (2015). Perspektif Amin Abdullah tentang Integrasi-Interkoneksi dalam Kajian Islam. Teosofi: Jurnal Tasawuf Dan Pemikiran Islam, 3(2), 376. https://doi.org/10.15642/teosofi.2013.3.2.376-409

Susetyo, S. (2020). Permasalahan Implementasi Kurikulum Merdeka Belajar Program Studi Pendidikan Bahasa Indonesia FKIP Universitas Bengkulu. Seminar Nasional Pendidikan Bahasa Dan Sastra, 1(1), $29-43$.

Tohir M. (2020). Buku Panduan Merdeka Belajar - Kampus Merdeka (kesatu). Direktorat Jenderal Pendidikan Tinggi Kementerian Pendidikan dan Kebudayaan.

Waston, W. (2016). Pemikiran Epistemologi Amin Abdullah Dan Relevansinya Bagi Pendidikan Tinggi Di Indonesia. Profetika: Jurnal Studi Islam, 17(01), 80-89. https://doi.org/10.23917/profetika.v17i01.2102 